\title{
In vivo proton magnetic resonance spectroscopy reveals region specific metabolic responses to SIV infection in the macaque brain Eva-Maria Ratai ${ }^{1,2}$, Sarah J Pilkenton ${ }^{1,2}$, Jane B Greco ${ }^{1,2}$, Margaret R Lentz ${ }^{1,2}$, Jeffrey P Bombardier ${ }^{1}$, Katherine W Turk ${ }^{1}$, Julian He ${ }^{1,2}$, Chan-Gyu Joo ${ }^{1,2}$, Vallent Lee $^{1}$, Susan Westmoreland ${ }^{2,3}$, Elkan Halpern ${ }^{2,4}$, Andrew A Lackner ${ }^{5}$ and R Gilberto González*1,2
}

\begin{abstract}
Address: ${ }^{1}$ Neuroradiology Division, Department of Radiology and A.A. Martinos Center for Biomedical Imaging, Massachusetts General Hospital, Charlestown, Massachusetts, 02129, USA, ${ }^{2}$ Harvard Medical School, Boston, Massachusetts, 02115, USA, ${ }^{3}$ New England Primate Research Center, Southborough, Massachusetts, 01772, USA, ${ }^{4}$ Institute for Technology Assessment, Department of Radiology, Massachusetts General Hospital, Charlestown, Massachusetts, 02129, USA and ${ }^{5}$ Tulane National Primate Research Center, Tulane University Health Science Center, Covington, Louisiana, 70433, USA

Email: Eva-Maria Ratai - ratai@nmr.mgh.harvard.edu; Sarah J Pilkenton - spilkenton@framingham.edu; Jane B Greco - jrb@alumni.caltech.edu; Margaret R Lentz - mlentz@nmr.mgh.harvard.edu; Jeffrey P Bombardier - bombardi@nmr.mgh.harvard.edu;

KatherineWTurk - kwtster@gmail.com; Julian He - hej@helix.mgh.harvard.edu; Chan-Gyu Joo - cjoo@nmr.mgh.harvard.edu;

Vallent Lee - vallent@nmr.mgh.harvard.edu; Susan Westmoreland - susan_westmorelant@hms.harvard.edu; Elkan Halpern - elk@mgh-ita.org; Andrew A Lackner - alackner@tpc.tulane.edu; R Gilberto González* - rggonzalez@partners.org

* Corresponding author
\end{abstract}

Published: 22 June 2009

BMC Neuroscience 2009, 10:63 doi:10.1/86/147/-2202-10-63
Received: 30 December 2008

Accepted: 22 June 2009

This article is available from: http://www.biomedcentral.com/I47I-2202/I0/63

(C) 2009 Ratai et al; licensee BioMed Central Ltd.

This is an Open Access article distributed under the terms of the Creative Commons Attribution License (http://creativecommons.org/licenses/by/2.0), which permits unrestricted use, distribution, and reproduction in any medium, provided the original work is properly cited.

\begin{abstract}
Background: In vivo proton magnetic resonance spectroscopy ('H-MRS) studies of HIV-infected humans have demonstrated significant metabolic abnormalities that vary by brain region, but the causes are poorly understood. Metabolic changes in the frontal cortex, basal ganglia and white matter in I 8 SIV-infected macaques were investigated using MRS during the first month of infection.

Results: Changes in the $\mathrm{N}$-acetylaspartate (NAA), choline (Cho), myo-inositol (MI), creatine ( $\mathrm{Cr}$ ) and glutamine/glutamate ( $\mathrm{Glx}$ ) resonances were quantified both in absolute terms and relative to the creatine resonance. Most abnormalities were observed at the time of peak viremia, 2 weeks post infection (wpi). At that time point, significant decreases in NAA and NAA/Cr, reflecting neuronal injury, were observed only in the frontal cortex. $\mathrm{Cr}$ was significantly elevated only in the white matter. Changes in $\mathrm{Cho}$ and $\mathrm{Cho} / \mathrm{Cr}$ were similar across the brain regions, increasing at 2 wpi, and falling below baseline levels at $4 \mathrm{wpi}$. $\mathrm{MI}$ and $\mathrm{MI} / \mathrm{Cr}$ levels were increased across all brain regions.
\end{abstract}

Conclusion: These data best support the hypothesis that different brain regions have variable intrinsic vulnerabilities to neuronal injury caused by the AIDS virus.

\section{Background}

Despite the successes of antiretroviral therapies, the neurocognitive complications of AIDS infection (neuroAIDS) continue to be an important problem [1]. Interestingly, clinical, neuropathological and imaging studies have demonstrated that the virus variably affects different 
regions of the brain [2-4]. In vivo ${ }^{1} \mathrm{H}$ MRS studies of chronically HIV infected patients have disclosed varying metabolic abnormalities in different brain regions $[5,6]$. Some have reported that the most profound MRS changes occur in the basal ganglia and white matter $[7,8]$ while others have reported significant changes in the frontal cortex of HIV patients, even in patients free of neurological symptoms [9].

The simian immunodeficiency virus (SIV)-infected rhesus macaque model is arguably the best animal model of neuroAIDS [10]. There are strong neuropathological similarities between HIV patients and SIV-infected macaques $[11,12]$. In vivo macaque brain ${ }^{1} \mathrm{H}$ MR spectra are similar to humans and post mortem and in vivo MRS studies from SIV infected macaques have revealed metabolic abnormalities [13-15] similar to those observed in HIV-infected human brains by in vivo MRS $[16,17]$. A power calculation conducted by Greco et al. revealed that single voxel MRS at 1.5 Tesla was capable of detecting changes similar to those observed in human MRS studies for most metabolites using less than 10 animals [18].

Eight of the animals reported on in this study were allowed to progress until terminal AIDS or the 2 year endpoint of the study. Pathology of the harvested brains revealed that two out of the eight animals developed SIVE encephalitis (SIVE) as defined by the presence of perivascular infiltrates of macrophages and multinucleated giant cells [19]. These findings are consistent with previous reports that neuropathological changes are variable, with SIV encephalitis developing in $25 \%$ of infected macaques [20] similar to the incidence of encephalitis in HIVinfected humans. Furthermore, spectroscopy on these animals revealed that an elevation of basal ganglia Cho/Cr at four weeks post-inoculation is predictive for the development of SIV encephalitis [19].

The objective of our study was to evaluate macaque brain regional variations during acute SIV infection. During the first month of SIV infection, very rapid changes in macaque blood viral load are observed [21] much like its human counterpart. We previously reported that profound metabolic changes occur in the frontal cortex of macaques in the first weeks after SIV infection [15]. To help understand brain region specific variations in HIV/AIDS, we evaluated the neurochemical changes observed by in vivo ${ }^{1} \mathrm{H}$ MRS in the basal ganglia and white matter, and compared them to the changes seen in the frontal cortex in 18 SIV-infected rhesus macaques. This study aims to reveal which brain regions are more susceptible to gliosis and neuronal injury during the primary phase of infection.

\section{Results}

A total of 18 rhesus macaques were infected with SIV, and imaged with in vivo ${ }^{1} \mathrm{H}$ MRS at multiple time points including pre-infection and up to 4 weeks after infection. ${ }^{1} \mathrm{H}$ MR spectra were separately acquired from 3 specific brain regions, frontal cortex, basal ganglia, and centrum semiovale, as illustrated in Figure 1. ${ }^{1} \mathrm{H}$ MR spectra with short echo time $(\mathrm{TE}=35 \mathrm{~ms})$ are characterized by resonances primarily arising from NAA, MI, Cr, Cho, and Glx (Figure 1). Peak viremia was observed at 11-12 days pi (dpi) with a mean plasma level of $5.8 \times 10^{7}$ copy eq. $/ \mathrm{mL}$. At 4 wpi, the mean plasma viral load was $4.0 \times 10^{6}$ copy eq./mL

A multivariate analysis of variance (MANOVA) was performed for all metabolites across all time points and brain regions, and highly significant differences were found ( $\mathrm{P}$ $<0.0001)$. Further analyses isolated temporal $(\mathrm{P}<$ $0.0001)$ and regional differences $(P=0.007)$. Below, we detail the temporal metabolic changes during the first 4 weeks of SIV infection, and the metabolic changes that occur in different brain regions.

\section{Temporal changes in metabolite concentrations during acute SIV infection}

The normalized changes in the mean concentrations of NAA, Cr, Cho, MI, and Glx after infection in each brain region are graphically displayed in Figure 2. Metabolite concentrations (average levels \pm SEM) and the results of the statistical analyses are listed in Table 1. P-values were obtained using repeated measures analysis of variance (RM ANOVA) on 12 animals measured before infection and at 2 and 4 wpi. If significant by RM ANOVA, Holm's t-tests were used to isolate differences between the time points. Additionally, paired ttests were performed on all 18 animals scanned before infection and 2 wpi. NS indicated that ANOVA or t-tests were not significant. The most significant changes were observed in the frontal cortex and were consistent with previous studies [15]. NAA is significantly decreased at 2 wpi but is not different from baseline at 4 weeks. Cho shows a trend towards increase at 2 wpi $(P=0.077)$ but falls below baseline levels at 4 wpi. MI increases at 2 wpi and remains elevated. Cr concentration did not change over time in the frontal cortex. Thus, changes in metabolite concentration and metabolite ratios with respect to $\mathrm{Cr}$ are similar. No change in frontal Glx was identified.

Interestingly, we found a significant increase in the $\mathrm{Cr}$ concentration at $2 \mathrm{wpi}$ in the white matter of the centrum semiovale. Similar to the frontal cortex, white matter Cho increases significantly at the time of peak viremia at $2 \mathrm{wpi}$ and decreases to a level below baseline at 4 weeks. Likewise, MI increases at 2 weeks and stays elevated at 4 weeks. However, NAA concentrations in the centrum semiovale show no significant differences during the first month of infection. A significant decrease in the white matter NAA/ $\mathrm{Cr}(7.5 \%$ decline, $\mathrm{P}=0.022)$ at 2 weeks is explained by an increase in $\mathrm{Cr}$ at that time point. Again, no significant $\mathrm{Glx}$ changes could be detected. 

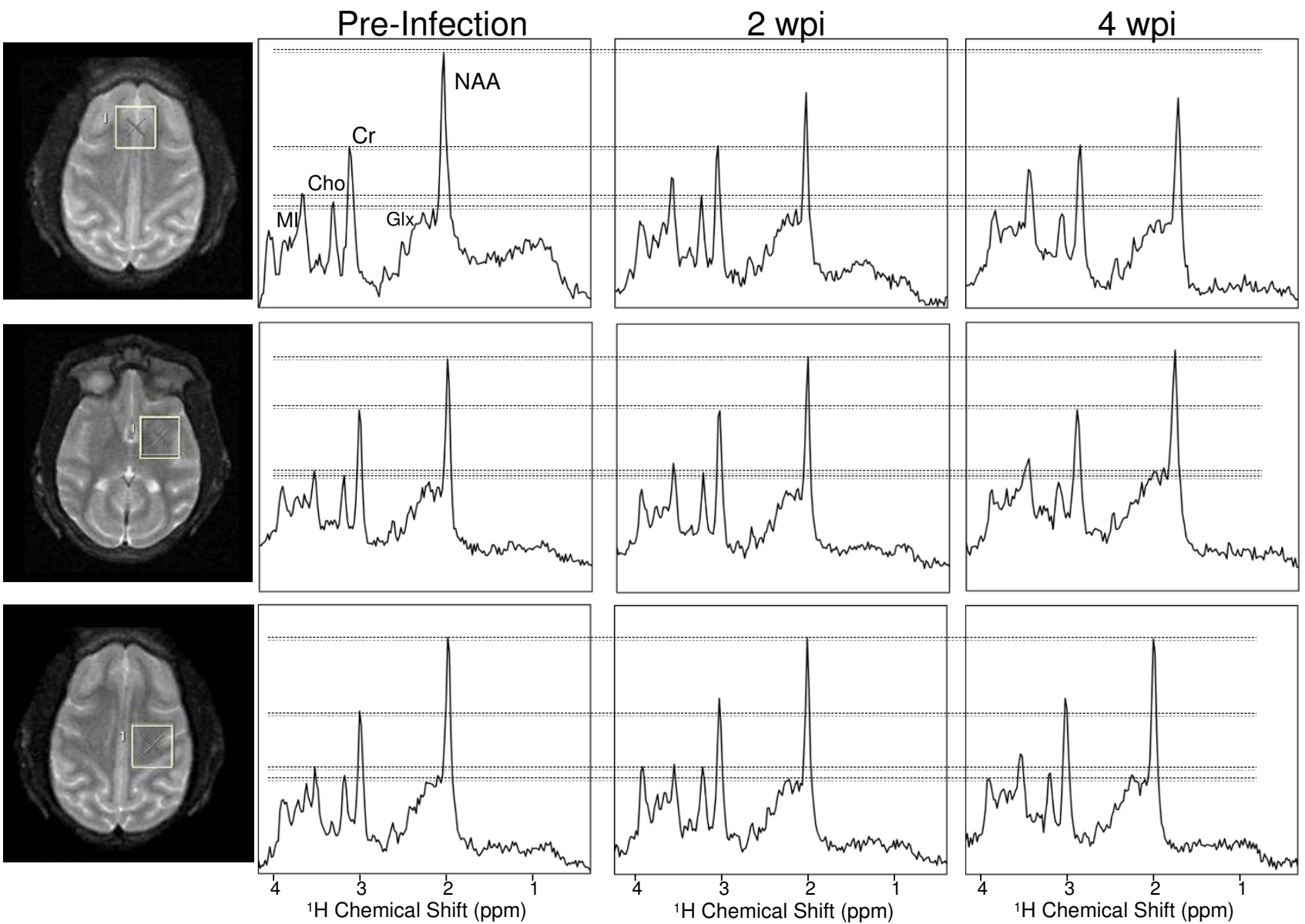

Figure I

Voxel locations (left) and corresponding representative spectra are shown for the frontal cortex (top), basal ganglia (middle), and white matter of the centrum semiovale (bottom). The major metabolites are labeled on the spectra, as well as dashed lines corresponding to pre-infection levels. Spectra are from a single representative animal, are not baseline corrected or apodized. Top: Frontal cortex MR spectra of a representative monkey before infection, at 2 and 4 wpi. Spectra are scaled to the creatine resonance because $\mathrm{Cr}$ levels did not change in frontal cortex during acute SIV infection. It can be seen from the spectra that NAA is decreased at 2, Cho is decreased at 4 wpi, and MI is increased at 2 and 4 wpi. (Due to the difficulty in finding spectra from a single animal that are representative of the group data in all aspects, we would like to note that the decrease in NAA at 4 wpi is not representative of the unchanged NAA concentration reflected in the group data). Middle: Basal ganglia MR spectra are scaled to the $\mathrm{Cr}$ peak as the $\mathrm{Cr}$ concentration did not change. No significant changes in NAA were observed. A decrease in Cho is evident by 4 wpi. Finally, an increase in MI can be observed from at 2 and 4 wpi. Bottom: White Matter MR spectra of a the same representative monkey before infection, at 2 and 4 wpi. Spectra are scaled to the NAA resonance because NAA levels did not change in white matter semiovale during acute SIV infection. It can be seen from the spectra that $\mathrm{Cr}$ is increased at $2 \mathrm{wpi}$, and $\mathrm{Cho}$ is increased and then decreased to baseline levels at 4 wpi. An increase in $\mathrm{Ml}$ can also be detected.

In the basal ganglia, absolute metabolite concentration changes over time were not statistically significant. However, while the Cho concentration did not change significantly at any time point after infection, Cho/Cr ratio did show a significant decline of $8.9 \%(\mathrm{P}=0.011)$ between 2 and 4 wpi. Inspection of the absolute concentration values of these 2 metabolites suggests that the change in the ratio is driven primarily by a decline in $\mathrm{Cho}$, and the lower variances observed in ratios accounts for the observation of the statistically significant decline. Notably, a decline in Cho/Cr between 2 and 4 wpi was also observed in the frontal cortex $(19.6 \%$ decline, $\mathrm{P}<0.0001)$ and the white matter $(10.5 \%$ decline, $\mathrm{P}=0.019)$. Basal ganglia NAA and Glx changes after infection were not significant. If present, they are within the experimental error of the measurements. 
Table I: Average levels \pm SEM of measured absolute metabolites in institutional units for NAA, GIx, Cr, Cho and MI in SIV infected macaques analyzed by in vivo MR spectroscopy

\begin{tabular}{|c|c|c|c|c|}
\hline & & Frontal Cortex & White Matter & Basal Ganglia \\
\hline \multirow[t]{8}{*}{ NAA } & Uninfected & $6.86 \pm 0.19$ & $7.94 \pm 0.24$ & $7.38 \pm 0.15$ \\
\hline & 2 wpi & $6.26 \pm 0.15$ & $7.82 \pm 0.13$ & $7.17 \pm 0.16$ \\
\hline & 4 wpi & $6.83 \pm 0.79$ & $7.92 \pm 0.65$ & $7.22 \pm 0.68$ \\
\hline & RM ANOVA & $P=0.025$ & NS & NS \\
\hline & Holm't t-test pre - 2 wpi. & $P=0.011$ & & \\
\hline & Holm's t-test pre -4 wpi & NS & & \\
\hline & Holm's t-test 2 wpi -4 wpi & $P=0.035$ & & \\
\hline & Paired t-test pre -2 wpi & $P=0.021$ & NS & NS \\
\hline \multirow[t]{8}{*}{ Glx } & Uninfected & $12.30 \pm 0.26$ & $\mid 1.71 \pm 0.32$ & $11.96 \pm 0.23$ \\
\hline & 2 wpi & $11.81 \pm 0.29$ & $1 \mathrm{I} .14 \pm 0.38$ & $11.07 \pm 0.29$ \\
\hline & 4 wpi & $12.80 \pm 0.29$ & $|1.26 \pm 0.3|$ & $12.03 \pm 0.30$ \\
\hline & RM ANOVA & NS & NS & NS \\
\hline & Holm't t-test pre -2 wpi & & & \\
\hline & Holm's t-test pre -4 wpi & & & \\
\hline & Holm's t-test 2 wpi -4 wpi & & & \\
\hline & Paired t-test pre -2 wpi & NS & NS & $P=0.052$ \\
\hline \multirow[t]{8}{*}{$\mathrm{Cr}$} & Uninfected & $5.60 \pm 0.09$ & $5.76 \pm 0.14$ & $6.65 \pm 0.10$ \\
\hline & 2 wpi & $5.450 \pm 0.13$ & $6.15 \pm 0.13$ & $6.49 \pm 0.08$ \\
\hline & 4 wpi & $5.78 \pm 0.10$ & $6.01 \pm 0.18$ & $6.53 \pm 0.14$ \\
\hline & RM ANOVA & NS & $P=0.025$ & NS \\
\hline & Holm't t-test pre -2 wpi & & $P=0.007$ & \\
\hline & Holm's t-test pre -4 wpi & & NS & \\
\hline & Holm's t-test 2 wpi -4 wpi & & NS & \\
\hline & Paired t-test pre -2 wpi & NS & $P=0.003$ & NS \\
\hline \multirow[t]{8}{*}{ Cho } & Uninfected & $1.014 \pm 0.03$ & $0.9754 \pm 0.04$ & $1.18 \pm 0.03$ \\
\hline & 2 wpi & $1.066 \pm 0.025$ & $1.078 \pm 0.05$ & $1.20 \pm 0.04$ \\
\hline & 4 wpi & $0.91 \pm 0.04$ & $0.9334 \pm 0.04$ & $1.10 \pm 0.06$ \\
\hline & RM ANOVA & $P<0.0001$ & $P=0.007$ & NS \\
\hline & Holm't t-test pre -2 wpi & $P=0.077$ & $P=0.008$ & \\
\hline & Holm's t-test pre -4 wpi & $P=0.016$ & NS & \\
\hline & Holm's t-test 2 wpi -4 wpi & $P<0.0001$ & $P=0.004$ & \\
\hline & Paired t-test pre -2 wpi & NS & NS & NS \\
\hline \multirow[t]{8}{*}{ MI } & Uninfected & $5.25 \pm 0.14$ & $4.72 \pm 0.18$ & $5.06 \pm 0.12$ \\
\hline & $2 \mathrm{wpi}$ & $5.81 \pm 0.08$ & $5.15 \pm 0.13$ & $5.21 \pm 0.15$ \\
\hline & 4 wpi & $5.98 \pm 0.23$ & $5.45 \pm 0.23$ & $5.45 \pm 0.18$ \\
\hline & RM ANOVA & $P=0.048$ & $P=0.033$ & NS \\
\hline & Holm't t-test pre -2 wpi & $P=0.080$ & $P=0.051$ & \\
\hline & Holm's t-test pre -4 wpi & $P=0.018$ & $P=0.013$ & \\
\hline & Holm's t-test 2 wpi -4 wpi & NS & NS & \\
\hline & Paired t-test pre -2 wpi & $P=0.003$ & $P=0.029$ & NS \\
\hline
\end{tabular}

P-values were obtained using repeated measures analysis of variance (RM ANOVA) on 12 animals measured before infection and at 2 and 4 wpi. If significant by RM ANOVA, Holm's t-tests were used to isolate differences between the time points. Additionally, paired t-tests were performed on all 18 animals scanned before infection and 2 wpi. NS indicated that ANOVA or t-tests were not significant.

\section{Correlations between metabolite concentration changes in different regions}

To determine whether metabolic markers, NAA, Cho, MI, $\mathrm{Cr}$ and Glx levels change in a similar fashion during acute SIV infection in the frontal cortex, white matter and basal ganglia, Spearman Rank correlation analyses were undertaken. Table 2 summarizes the correlations between metabolite concentration changes in different regions. The rationale for correlating the changes of metabolites in different brain regions was to determine if the metabolic responses were uniform throughout the brain or if some regions are affected to a greater extent. We interpret posi- tive correlations to mean that the responses to infection are similar in different brain regions, and that the responses are different when they do not correlate.

No significant correlations between NAA concentration changes in the frontal cortex and white matter, and between frontal cortex and basal ganglia NAA were found. While no significant temporal changes in NAA were found in the basal ganglia or white matter, Spearman Rank analysis revealed a significant association between white matter and basal ganglia changes $\left(P=0.0049, R_{s}=0.50\right)$. For the choline changes, Spearman Rank analyses revealed 

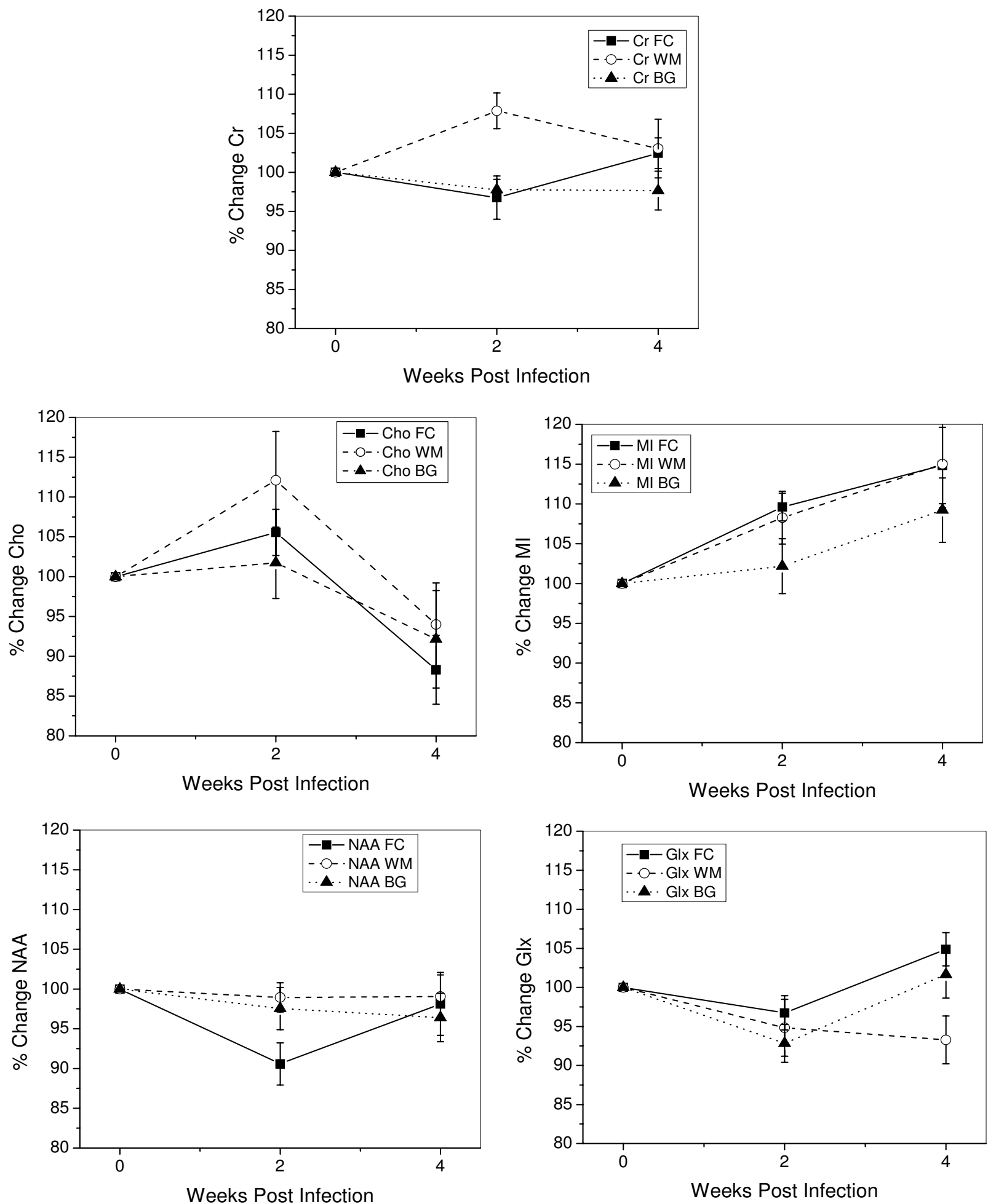

Figure 2

Temporal spectroscopic changes observed in the normalized absolute concentrations of $\mathrm{Cr}, \mathrm{Cho}$, MI, NAA, and GIx in SIV-infected rhesus macaques measured in the frontal cortex (FC), white matter (WM) and basal ganglia (BG). Statistics are given in Table I. 
Table 2: Spearman Rank correlation analyses of metabolite concentrations between different brain regions of the SIV infected macaques.

\begin{tabular}{|c|c|c|c|c|c|c|c|c|c|c|}
\hline & $N A A$ & & Glx & & $\mathrm{Cr}$ & & Cho & & MI & \\
\hline $\begin{array}{l}\text { Spearman Rank } \\
\text { FC - WM }\end{array}$ & $\mathbf{R}_{\mathrm{s}}$ & $\begin{array}{l}\mathbf{p} \\
\text { NS }\end{array}$ & $\begin{array}{l}\mathbf{R}_{\mathrm{s}} \\
0.32\end{array}$ & $\begin{array}{l}P \\
0.088\end{array}$ & $\mathbf{R}_{\mathrm{s}}$ & $\begin{array}{l}\mathbf{p} \\
\text { NS }\end{array}$ & $\begin{array}{l}R_{s} \\
0.52\end{array}$ & $\begin{array}{l}\mathrm{p} \\
0.0032\end{array}$ & $\mathbf{R}_{\mathrm{s}}$ & $\begin{array}{l}\mathbf{p} \\
\text { NS }\end{array}$ \\
\hline FC - BG & & NS & 0.52 & 0.0034 & & NS & 0.36 & 0.052 & 0.37 & 0.043 \\
\hline WM - BG & 0.50 & 0.0049 & & NS & & NS & 0.54 & 0.0021 & & NS \\
\hline
\end{tabular}

For this purpose the percent change from baseline were calculated for each individual monkey for all time points. Significant $\mathrm{P}$-values are noted in bold. $\mathrm{P}$-values with a trend towards significance $(\mathrm{P}<0.1)$ are noted italics and non-significant differences are indicated by NS. However, it must be noted that when the correlations are subjected to Bonferroni correction, a P-value of $<0.0033$ is required for significance.

correlations between all three brain regions (frontal cortex vs. white matter $\mathrm{P}=0.0032, \mathrm{R}_{\mathrm{s}}=0.52$; frontal cortex vs. basal ganglia $\mathrm{P}=0.052, \mathrm{R}_{\mathrm{s}}=0.36$ and white matter vs. basal ganglia $\left.\mathrm{P}=0.0021, \mathrm{R}_{\mathrm{s}}=0.54\right)$. MI changes were correlated between frontal cortex and basal ganglia $(\mathrm{P}=$ $0.043, \mathrm{R}_{\mathrm{s}}=0.37$ ), but not between white matter and the other two regions. There was no significant correlation between $\mathrm{Cr}$ concentration changes in the three brain regions. Finally, Glx changes were correlated between frontal cortex and basal ganglia $\left(P=0.0034, R_{s}=0.05\right)$, but, no correlation was found between white matter and basal ganglia. A trend was found between Glx changes in the frontal cortex and white matter.

\section{Correlations between metabolite concentration changes and plasma viral loads}

We also investigated correlations between plasma viral load and metabolite concentration changes in the 3 volumes of interest (VOIs). Viral load data was obtained from 8 animals at 2 and/or 4 wpi for a total of 10 data points. Using Spearman Rank, we found a significant correlation between the change in the $\mathrm{Cho/Cr}$ ratio in the frontal cortex and change in the plasma viral loads at 2 and 4 weeks combined $\left(\mathrm{R}_{\mathrm{s}}=0.67, \mathrm{P}=0.035\right)$. In addition, we found a correlation between plasma viral loads and Cho/Cr changes in the basal ganglia $\left(R_{s}=0.70, P=0.009\right)$ and Cho changes in BG $\left(\mathrm{R}_{\mathrm{s}}=0.77, \mathrm{P}=0.02\right)$. There was no relationship between WM changes and plasma viral loads. Furthermore, there was no relationship between any of the other metabolite concentrations/ratios and viral loads. However, due to the small sample size, we consider these analyses highly preliminary.

\section{Discussion}

A long-standing observation in patients infected with HIV is that different parts of the brain appear to be variably affected by the virus. Evidence for variable response to the virus by different brain regions has come from clinical, pathological and imaging studies. To help gain a better understanding of this phenomenon, we used in vivo ${ }^{1} \mathrm{H}$ MR spectroscopy to probe how different regions of the macaque brain respond metabolically during the first month of SIV infection, a time point not normally acces- sible by clinical studies. At the time of peak viremia, a transient decline in the NAA resonance, reflecting temporary neuronal injury, was only detected in the frontal cortex. On the other hand, changes in Cho and MI were similar across brain regions. The $\mathrm{Cr}$ resonance appeared stable in all regions and times with the exception of white matter where a transient increase was observed at peak viremia.

\section{Evidence of neuronal injury is detected only in the frontal cortex}

A decrease in NAA is only observed in the frontal cortex at 2 wpi, the time of peak viremia. NAA is almost exclusively located in neurons, and a decrease in NAA reflects neuronal loss [22,23] or reversible neuronal injury [24,25]. Lentz et al. showed that encephalitis severity correlates with decreased NAA/Cr levels in the frontal cortex in the macaque model of neuroAIDS $[26,27]$. With the reduction of SIV plasma viral load by 1-2 orders of magnitude at 4 wpi, NAA levels are also no longer abnormal, suggesting that partial immunologic control of the virus is sufficient to result in neuronal recovery. The selective neuronal vulnerability of frontal cortex to SIV infection is further supported by the observation of significant decreases in synaptophysin (SYN) in the frontal cortex but not in the basal ganglia (unpublished results). SYN is an integral membrane glycoprotein in presynaptic vesicles. Its decline indicates a disruption in synaptic transmission and it is therefore a sensitive marker of neuronal dysfunction. We have previously shown that SYN is highly correlated to in vivo NAA/Cr measurements in this same SIV/macaque model of neuroAIDS [24].

\section{Choline changes in the same manner in the brain regions}

The Cho levels appear to change in a similar fashion in all brain regions after SIV infection. This implies that the changes are global, and not specific to any particular brain region. MI increased significantly in the FC and WM, and MI changes correlated between frontal cortex and basal ganglia $\left(P=0.043, R_{s}=0.37\right)$, but not between white matter and the other two regions. It must be noted that when the correlations are subjected to Bonferroni correction, the MI correlations lose significance, however, the choline correla- 
tions between the regions remain significant after Bonferroni correction. At the time of peak viremia, Cho levels are elevated, and they decrease to baseline levels or lower with a reduction of plasma viral load at 4 wpi. An increase in Cho may reflect altered membrane metabolism [28], and may be associated with cerebral inflammation. Its elevation is believed to reflect cellular responses, including cell proliferation, recruitment, microgliosis, and/or astrocytosis in neuroAIDS [29,30]. Evidence of the association with astrocytosis is given by our observations of elevated GFAP at the same time point in this model [31].

In a previous report [15] we reported that Cho levels in the frontal cortex decreased to levels significantly below baseline by 4 wpi. In extending our analyses to other regions we find that at 4 wpi Cho levels are below baseline in the white matter and basal ganglia, but these are not significant. However, significant declines in Cho were observed in all 3 regions between 2 and 4 wpi, a period when viral loads are substantially reduced. The best interpretation of this observation is that it is a manifestation of brain recovery and healing.

Cerebral MI increased almost linearly after SIV infection. $\mathrm{MI}$ is located primarily in glia; thus, elevation of $\mathrm{MI}$ is considered to reflect increased glial cell activity [32]. An elevation of MI has been commonly reported in studies of chronically infected HIV patients $[9,16]$. The increases in MI were not as highly correlated between the brain regions, but they appeared to increase in all 3 regions almost linearly up to 4 wpi. We have previously reported that there is a complex relationship between astrocytosis and MI, as well as between astrocytosis and Cho [31]. The data reported here on Cho and MI continue to support a complex relationship among these measurements that occur when the animal is infected. Further studies are necessary to elucidate the relationships.

\section{Creatine increases during acute SIV infection in white matter}

At the time of peak viremia, $\mathrm{Cr}$ concentrations were significantly increased in the white matter of the centrum semiovale. Changes in total $\mathrm{Cr}$ (phosphocreatine and creatine) are associated with altered energy metabolism. Elevated Cr levels have been reported in the frontal white matter of chronic HIV patients [33]. It is believed that the virus enters the brain through infected monocytes that later differentiate into macrophages [34,35]. During this process of mononuclear cell infiltration, glial-cell activation and proliferation may manifest high tissue metabolism which would explain an increase in Cr. Energy change as a function of enhanced glial activation is supported by our finding that the greatest increases in $\mathrm{MI}$ and Cho are in the same regions as the highest increase in $\mathrm{Cr}$ (Figure 2). Our finding that creatine changes are not uni- form across the brain regions is consistent with the study by Chang et al. [33] who reported creatine increases in the white matter but decreases in the basal ganglia in later stages of AIDS dementia complex.

\section{Comparison of HIV and SIV}

Most HIV MRS studies are performed during the chronic stage of infection, often with subjects who are on antiretroviral therapy. Our macaque study focuses on acute SIV infection, a period that has not yet been studied by MRS in HIV infection. Acute SIV infection induces the most profound NAA changes in the frontal cortex, and more subtle and difficult to detect changes in the basal ganglia and white matter. We hypothesize that HIV in humans might produce similar responses during the primary infection as those described here. During primary infection, HIV and SIV proliferate to very high levels for a short time. As the immune system responds to the infection, plasma virus drops to lower levels. There may be recurrence of high viremia with the progressive weakening of the immune system by the virus. Anti-retroviral therapy will suppress viral production at this stage. It is only at the last stage, with the collapse of the immune system, that very high viremia is once again observed. There are very few reported MRS studies of people with early [17] or late high viremia $[36,37]$. It is possible that the difference in viral loads in patients is the most important factor responsible for differences MRS patterns that have been reported.

The macaque model has similar MR spectroscopic changes (diminished NAA, elevated Cho and MI) as in human neuroAIDS, suggesting that neurochemical and cellular responses to SIV and HIV are similar. However, the specific pattern of MRS changes in various brain regions of the acutely SIV-infected macaque appears different from that seen in humans. Both, single voxel MRS and magnetic resonance spectroscopic imaging (MRSI) studies performed before the advent of anti-retroviral therapy demonstrated profound declines in the levels of NAA in advanced cognitively impaired patients $[29,38,39]$. In the early stages of cognitive dysfunction, $\mathrm{Cho} / \mathrm{Cr}$ and $\mathrm{MI} / \mathrm{Cr}$ were shown to be elevated prior to changes in NAA [40].

More recently in the anti-retroviral era, in vivo ${ }^{1} \mathrm{H}$ MRS studies of HIV patients have consistently found metabolic abnormalities in different brain regions $[5,6]$. Some groups have reported that the most profound MRS changes occur in the basal ganglia and white matter $[7,8]$. Others have reported significant changes in the frontal cortex of HIV patients, even in patients free of neurological symptoms [9]. Additionally, recent high spatial resolution neuroimaging investigations using sophisticated analytic methods have found diminution in the thickness of the cortical mantle [41]. 
In this study we found region specific responses with respect to NAA but not choline. MRSI studies investigating the regional metabolic responses in HIV infected patients with HIV associated dementia were found to be quite variable. Some report evidence of uniform metabolic abnormalities (decreased NAA/Cr [39] and increased Cho/Cr) in various brain regions and conclude that abnormalities of cerebral metabolites in HIV-infected patients may be part of a diffuse process [42]. However, some MRSI studies observe NAA/Cr decreases [16] and Cho/Cr increases [43] in gray matter regions and not in white matter in patients with AIDS dementia complex. Additionally, Barker et al. reported that the largest reductions in NAA and increases in Cho were in the frontal lobe white matter and there were no changes in the cortical gray matter [38]. This great variability could be the result of many factors including: disease stage; the presence, type and duration of antiretroviral treatment; co-morbidities including drug abuse; and differences in imaging parameters such as pulse sequence, TE and TR.

We also investigated potential correlations between plasma viral load and metabolite concentration changes. We previously reported [15] a significant relationship between changes in Cho/Cr and plasma viral loads $\left(\mathrm{R}_{\mathrm{s}}=\right.$ $0.79, \mathrm{P}<0.01$ ) by Spearman Rank correlation analyses. Here, we found a correlation between plasma viral loads and $\mathrm{Cho} / \mathrm{Cr}$ changes in the basal ganglia and Cho changes in BG. There was no relationship between WM Cho changes and plasma viral loads or between any of the other metabolite concentrations/ratios and viral loads. These preliminary findings are different from what has been reported for patients with HIV, however, our study focuses on the acute phase of infection, unlike human studies which involve chronically infected individuals. Among HIV+ patients higher plasma viral loads are typically associated with lower NAA [44] and higher MI [33]. Another study reported that CSF but not plasma viral load correlated with $\mathrm{Cho} / \mathrm{Cr}$ in the white matter [45]. Again, there are many potential reasons for differences in correlations that have been reported between viral loads and MRS metabolites.

\section{Possible mechanisms of regional brain metabolic abnormalities}

The leading theory of neuroAIDS pathogenesis is that infected/activated monocytes traffic into the CNS, where they differentiate into macrophages, and set off a cascade of events that ultimately result in neuronal injury [46]. One possibility that may explain regional variations in brain injury is that there are differences in the rate of monocyte trafficking into various brain regions. However, the similarity in the changes in Cho and MI observed in all regions suggests that the trafficking is globally similar. This is supported by the finding of similar astrocytic activation in frontal cortex and basal ganglia (unpublished results). However, while the evidence suggests that viral invasion is globally similar, neuronal injury is selective to the frontal cortex. Cortical neurons may be more susceptible to injury or neuronal protective/recovery mechanisms may be more effective in other regions.

The relationship of brain metabolic changes with respect to the level of virus in the blood is important. The greatest changes in NAA, Cho and $\mathrm{Cr}$ occur at the time of peak viremia followed by near normalization within 2 weeks. This sensitivity of the brain to events in the blood indicates a highly dynamic pathogenic process with the rapid transit of virally-infected monocytes into the brain and an equally rapid response by the brain to these events. The highly dynamic nature is further supported by the rapid normalization as plasma viral load decreases. Notably, this normalization occurs despite persistent virus in the blood, although not at peak levels. This observation suggests there may be a competition between pathogenic and protective mechanisms, and that a threshold level of viral load and trafficking, virally-infected monocytes must be exceeded for brain metabolic response to be manifested.

\section{Patient Management}

Our results imply that the virus has a global effect on microgliosis and astrogliosis. However, only cortical regions, here the frontal cortex, are affected by neuronal injury, suggesting that some regions of the brain are more vulnerable to invasion by SIV or HIV infected macrophages. These results may support the use of a combination of antiretroviral therapy early to decrease influx of infected/activated monocytes/macrophages that lead to inflammation and neuroprotective drugs which pass the BBB in order to prevent neuronal injury in region of the brain in which the innate recovery mechanisms fail.

MR spectroscopy should be considered for use in clinical HIV patient care to monitor changes in metabolism indicative of neuronal dysfunction possibly predictive of cognitive dysfunction. Single voxel MRS [29,33,47] as well as magnetic resonance spectroscopic imaging (MRSI) $[16,30,36,38,39,42,43,48,49]$ have been performed on patients with HIV dementia. Single voxel MRS has been commonly used since it is a shorter scan (for one voxel location) and requires less data processing. However, MRSI is a much more efficient technique to record MR spectroscopy data since it examines multiple regions in one data acquisition. Both techniques have shown significant changes in metabolite concentration in individuals with neuroAIDS and offer complementary information and should be used in conjunction as suggested by Sacktor [43] if time allows.

\section{Conclusion}

In summary, during acute SIV infection, changes in Cho and MI were similar across brain regions while a signifi- 
cant decrease in NAA, a marker of neuronal injury, was found in the frontal cortex only. A potential mechanism for these observations is that trafficking of infected monocytes involves all brain regions producing cellular changes (astrocytosis, microgliosis) that are reflected in elevations in Cho and MI. However, the data suggest that there is variable regional susceptibility to neuronal injury. With respect to clinical HIV patient management, the data from this model suggests that while the virus has global effects such as astrogliosis, cortical regions may be more susceptible to neuronal injury and merit observation, perhaps with the inclusion of clinical MRS studies. Moreover, the use of neuroprotective agents may be particularly useful in the protection of cortical neuronal integrity. The SIVinfected macaque model monitored with ${ }^{1} \mathrm{H}$ MRS is an excellent tool to further delineate the precise neuropathogenic mechanisms and to help assess the value of drugs that may used as adjunctive therapy whose purpose is the maintenance of cognitive normality.

\section{Methods \\ Animals}

The animals were housed according to the standards of the American Association for Accreditation of Laboratory Animal Care. Investigators adhered to the Guide for the Care and Use of Laboratory Animals of the Institute of Laboratory Animal Resources, National Research Council. The study was approved by the Massachusetts General Hospital Subcommittee on Research Animal Care and the Institutional Animal Care and Use Committee of Harvard University. Eighteen juvenile rhesus macaques (Macaca mulatta) of both sexes were included in the in vivo MRS study. All 18 animals had MR scans prior to infection with SIVmac251 (50 ng p27/kg) [50]. A second MR scan was obtained at 2 weeks post infection (wpi). Twelve of the eighteen animals underwent a third MR examination at 4 wpi. This imaging schedule was adopted because acutely infected macaques are unable to tolerate more frequent scanning. Animals were housed at the New England Regional Primate Research Center and transported to the Massachusetts General Hospital/A.A. Martinos Center for Biomedical Imaging. For imaging, the animals were tranquilized with ketamine or telazol and anesthetized with sodium pentobarbital. Six of these animals were sacrificed during the acute SIV infection for postmortem studies (ex vivo MR spectroscopy and quantitative neuropathologic analysis) the day after they underwent their last MR examination [24,31]. Eight of the remaining 12 animals were also included in the previously reported longitudinal in vivo ${ }^{1} \mathrm{H}$ MR spectroscopy study [19].

\section{MRI and MRS Studies}

Both MRI and ${ }^{1} \mathrm{H}$ MRS were performed using a standard GE linear extremity coil on a clinical 1.5 Tesla General Electric (Milwaukee, Wisconsin) Signa Scanner with an operating system of Horizon 8.3. First, a three-plane localizer was performed to position the monkey in the coil. In this manner, voxel placement was highly reproducible. A sagittal T1-weighted image sequence $(\mathrm{TE} / \mathrm{TR}=20 / 600)$ was utilized, followed by an axial dual echo pulse sequence $(\mathrm{TE}(1)=30 \mathrm{~ms} ; \mathrm{TE}(2)=80 \mathrm{~ms} ; \mathrm{TR}=2500 \mathrm{~ms})$ consisting of proton-weighted and T2-weighted images from which the ${ }^{1} \mathrm{H}$ MRS voxels were prescribed. With the exception of a slightly smaller voxel size, the MRS protocol was identical to the one employed in multicenter human HIV studies [5]. MRS was performed on each animal in frontal cortical gray matter, white matter semiovale and putamen using a voxel size of $15 \mathrm{~mm} \times 15 \mathrm{~mm} \times 15$ $\mathrm{mm}\left(3.4 \mathrm{~cm}^{3}\right)$ (Figure 1). Data were acquired using an automated PROBE-P spectroscopy package [51], which consists of a PRESS sequence $(\mathrm{TE}=35 \mathrm{~ms}, \mathrm{TR}=3000 \mathrm{~ms}$, number of acquisitions $=128$ ) [52] with CHESS water suppression [53].

All spectra were processed offline using the LCModel software package [54] to determine the quantities of the brain metabolites $\mathrm{N}$-acetylaspartate and $\mathrm{N}$-acetylaspartylglutamate (collectively referred to as NAA), choline-containing compounds (referred to as Cho), MI, creatine-containing compounds (referred to as $\mathrm{Cr}$ ) and the so-called Glx concentration (while glutamate and glutamine represent the largest contributors to this peak area, we are aware that at 1.5T field strengths Glx will also include resonances from GABA, NAA, aspartate, and possibly succinate). Metabolite concentrations were estimated using the unsuppressed water signal from the same voxel, which served as the internal standard [55]. Absolute concentrations given by LCModel are normalizations of each resonance to the water peak, resulting in institutional units. Only if the tissue water concentration and $\mathrm{T} 1$ and $\mathrm{T} 2$ relaxation effects were estimated correctly, these units reflect a millimolar concentration. Metabolite ratios with respect to creatine were also calculated.

It is possible that alterations in metabolite transverse (T2) relaxation times are responsible for changes in metabolite resonance signals [56]. That is unlikely in the experiments reported here for several reasons. First, during the first month of SIV infection, we did not observe any signal changes on the anatomic $\mathrm{T} 2$ weighted images in these macaque brains suggesting little if any T2 effects. Additionally, some signal intensities increase at the same time that others decrease. If $\mathrm{T} 2$ changes were responsible, then some metabolites would be experiencing a prolongation in the transverse relaxation time while it would be shortened in others, a highly unlikely scenario. Moreover, we have previously reported high correlations between in vivo NAA measurements and post mortem tissue extract levels of this metabolite. The ex vivo measurements are made using a single pulse, long TR method thus eliminating T2 effects. 


\section{Viral loads}

After the MRI/MRS examination, blood samples were drawn from each animal to determine viral loads. Virionassociated SIV RNA in plasma was measured by using a real-time reverse transcription-PCR assay on an Applied Biosystems (Foster City, CA) Prism 7700 sequence detection system as described previously $[57,58]$. Results are averages of duplicate determinations.

\section{Statistical Methods}

The preinfection values of each metabolite were different in the three brain regions. Thus for clarity, the data were normalized by setting the average preinfection metabolite concentration to 100 percent. Data taken at subsequent time points were normalized by multiplying by the same proportionality factor specific to brain region and metabolite. To test our hypothesis that all major cerebral metabolites are changing with time after SIV infection in a region-dependent manner, a multivariate analysis of variance (MANOVA) was performed with respect to metabolite, time post infection and brain region. Post hoc repeated measures analyses of variance (RM ANOVAs) for individual metabolites across time and region were carried out only if the MANOVA was significant ( $\mathrm{p}<0.05$ ). MRS studies of uninfected macaques demonstrated that the standard deviation between scans of the same animal at different times was much smaller than the standard deviation between animals [18]. Statistical analyses of metabolite concentrations and metabolite ratios were performed using RM ANOVA on the data from the 12 animals that were scanned before infection, at 2 and 4 weeks after infection. If significant by RM ANOVA, Holm's ttests, which correct for multiple comparisons, were used to isolate significant differences between time points.

For the 18 animals scanned at 0 and 2 wpi, paired t-tests were used to compare preinfection scans to the 2 week pi scans. A p-value of less than 0.05 was considered significant. To assess interrelationships between metabolites in the three brain regions, Spearman Rank correlation coefficients were used to assess potential associations between regions for each metabolic marker. Again, a P-value of less than 0.05 was considered to indicate a statistically significant correlation. However, it must be noted that when the correlations are subjected to Bonferroni correction (five metabolites and 3 regions), a P-value of $<0.0033$ is required for significance. Additionally, potential relationships between plasma viral loads and brain metabolite changes at 2 and 4 weeks combined were assessed using Spearman Rank correlations. Finally, a power calculation was performed based on metabolite concentrations acquired from four animals that were scanned $\leq 4$ times pre inoculation over a period of 2 years. We found the highest reproducibility in $\mathrm{Cr}>\mathrm{Glx}>\mathrm{NAA}>\mathrm{MI}>\mathrm{Cho}$. The minimum detectable difference was between 5 and $16 \%$ for the metabolites with $80 \%$ power and a $5 \%$ significance level, in 18 animals.

\section{List of abbreviations used}

NAA: N-acetylaspartate; Cr: Creatine; Cho: choline containing compounds; MI: myo-inositol; Glx: glutamate and glutamine; SIV: simian immunodeficiency virus; HIV: human immunodeficiency virus; CNS: central nervous system: MRS: magnetic resonance spectroscopy; MRSI: magnetic resonance spectroscopic imaging; wpi: weeks post infection, GFAP: glial fibrillary acidic protein; SYN: synaptophysin.

\section{Authors' contributions}

EMR participated in the acquisition, statistical analysis and interpretation of the data and drafted the manuscript. SJP participated in the data analysis and interpretation of data and helped drafting the manuscript. JBG supervised and participated in the imaging experiments and analysis. MRL helped supervise and conduct imaging experiments, participated in image analysis and helped conduct statistical analysis. JPB participated in the statistical analysis and interpretation of the data and helped drafting the manuscript. KWT participated in the analysis of data. JH participated in animal care during imaging experiments, and participated in image analysis. CGJ participated in the analysis of data. VL helped drafting the manuscript. SVW participated on animal care and conducted pathologic evaluations. EH supervised and helped conduct statistical analysis. AAL participated in the design of the study, supervised animal care and pathologic evaluations. RGG conceived of the study, participated in its design and directed its execution. All authors read and approved the final manuscript.

\section{Acknowledgements}

We thank Drs. Angela Carville and Elisabeth Ludlage-Moeller for animal care at the NERPRC, Eric Broadbent and Ernest Neale for veterinary technical assistance, Elizabeth Curran and Mike O'Connell for pathology support, and Robert Fuller and John Kim for participating in MR experiments and analysis. This work was supported by grants from the $\mathrm{NIH}$, including National Center for Research Resources (NCRR) RRI32I4, RRI32I3, NS34626 (to RGG), and RR000I 50 and RR00 I 68 (to NERPRC), NS05 I I 29 (MRL), NS30769 and MH6II 92 (to AAL), R2INS05933I (to EMR), and National Institute of Allergy and Infectious Diseases A102869l (to EMR). The MGH A.A. Martinos Center for Biomedical Imaging is also supported by P4IRR I 4075 (National Center for Research Resources grant) and the Mental Illness and Neuroscience Discovery (MIND) Institute.

\section{References}

I. Nath A, Schiess N, Venkatesan A, Rumbaugh J, Sacktor N, McArthur J: Evolution of HIV dementia with HIV infection. Int Rev Psychiatry 2008, 20(I):25-3I.

2. Navia BA, Cho ES, Petito CK, Price RW: The AIDS dementia complex: II. Neuropathology. Ann Neurol 1986, I 9(6):525-535.

3. Wiley CA, Soontornniyomkij V, Radhakrishnan L, Masliah E, Mellors J, Hermann SA, Dailey P, Achim CL: Distribution of brain HIV load in AIDS. Brain Pathol 1998, 8(2):277-284. 
4. Moore DJ, Masliah E, Rippeth JD, Gonzalez R, Carey CL, Cherner M Ellis RJ, Achim CL, Marcotte TD, Heaton RK, et al:: Cortical and subcortical neurodegeneration is associated with HIV neurocognitive impairment. Aids 2006, 20(6):879-887.

5. Lee PL, Yiannoutsos CT, Ernst T, Chang L, Marra CM, Jarvik JG, Richards TL, Kwok EW, Kolson DL, Simpson D, et al.: A multi-center I H MRS study of the AIDS dementia complex: validation and preliminary analysis. J Magn Reson Imaging 2003, I 7(6):625-633.

6. Yiannoutsos CT, Ernst T, Chang L, Lee PL, Richards T, Marra CM, Meyerhoff DJ, Jarvik JG, Kolson D, Schifitto G, et al.: Regional patterns of brain metabolites in AIDS dementia complex. Neuroimage 2004, 23(3):928-935.

7. Suwanwelaa N, Phanuphak P, Phanthumchinda K, Suwanwela NC, Tantivatana J, Ruxrungtham K, Suttipan J, Wangsuphachart S, Hanvanich M: Magnetic resonance spectroscopy of the brain in neurologically asymptomatic HIV-infected patients. Magn Reson Imaging 2000, I 8(7):859-865.

8. Wilkinson ID, Lunn S, Miszkiel KA, Miller RF, Paley MN, Williams I, Chinn RJ, Hall-Craggs MA, Newman SP, Kendall BE, et al:: Proton MRS and quantitative MRI assessment of the short term neurological response to antiretroviral therapy in AIDS. J Neurol Neurosurg Psychiatry 1997, 63(4):477-482.

9. Chang L, Ernst T, Leonido-Yee M, Walot I, Singer E: Cerebral metabolite abnormalities correlate with clinical severity of HIV-I cognitive motor complex. Neurology 1999 , 52(I): $100-108$.

10. Burudi EM, Fox HS: Simian immunodeficiency virus model of HIV-induced central nervous system dysfunction. Adv Virus Res 200I, 56:435-468.

II. Zink MC, Amedee AM, Mankowski JL, Craig L, Didier P, Carter DL, Munoz A, Murphey-Corb M, Clements JE: Pathogenesis of SIV encephalitis. Selection and replication of neurovirulent SIV. Am J Pathol I997, I 5 I (3):793-803.

12. Sharer LR, Baskin GB, Cho ES, Murphey-Corb M, Blumberg BM, Epstein LG: Comparison of simian immunodeficiency virus and human immunodeficiency virus encephalitides in the immature host. Ann Neurol 1988, 23(Suppl):SI08-II 2

13. Tracey I, Lane J, Chang I, Navia B, Lackner A, Gonzalez RG: IH magnetic resonance spectroscopy reveals neuronal injury in a simian immunodeficiency virus macaque model. J Acquir Immune Defic Syndr Hum Retrovirol 1997, I 5(I):2I-27.

14. Gonzalez RG, Cheng LL, Westmoreland SV, Sakaie KE, Becerra LR, Lee PL, Masliah E, Lackner AA: Early brain injury in the SIVmacaque model of AIDS. Aids 2000, I 4(I 8):284I-2849.

15. Greco JB, Westmoreland SV, Ratai EM, Lentz MR, Sakaie K, He J, Sehgal PK, Masliah E, Lackner AA, Gonzalez RG: In vivo IH MRS of brain injury and repair during acute SIV infection in the macaque model of neuroAIDS. Magn Reson Med 2004, 5 I(6): II08-III4.

16. Lopez-Villegas D, Lenkinski RE, Frank I: Biochemical changes in the frontal lobe of HIV-infected individuals detected by magnetic resonance spectroscopy. Proc Natl Acad Sci USA 1997, 94(18):9854-9859.

17. Lentz MR, Kim WK, Lee V, Bazner S, Halpern EF, Venna N, Williams $\mathrm{K}$, Rosenberg ES, Gonzalez RG: Changes in MRS neuronal markers and $T$ cell phenotypes observed during early HIV infection. Neurology 2009, 72(17): | $465-1472$

18. Greco JB, Sakaie KE, Aminipour S, Lee PL, Chang LL, He J, Westmoreland S, Lackner AA, Gonzalez RG: Magnetic resonance spectroscopy: an in vivo tool for monitoring cerebral injury in SIVinfected macaques. J Med Primatol 2002, 3 I (4-5):228-236.

19. Fuller RA, Westmoreland SV, Ratai E, Greco JB, Kim JP, Lentz MR, He J, Sehgal PK, Masliah E, Halpern E, et al.: A prospective longitudinal in vivo IH MR spectroscopy study of the SIV/macaque model of neuroAIDS. BMC Neurosci 2004, 5(I): 10

20. Westmoreland SV, Halpern E, Lackner AA: Simian immunodeficiency virus encephalitis in rhesus macaques is associated with rapid disease progression. J Neurovirol 1998, 4(3):260-268.

21. Reimann KA, Tenner-Racz K, Racz P, Montefiori DC, Yasutomi Y, Lin W, Ransil B], Letvin NL: Immunopathogenic events in acute infection of rhesus monkeys with simian immunodeficiency virus of macaques. J Virol 1994, 68(4):2362-2370.

22. Moffett JR, Namboodiri MA, Cangro CB, Neale JH: Immunohistochemical localization of $\mathbf{N}$-acetylaspartate in rat brain. Neuroreport 199|, 2(3): |3|-|34.
23. Urenjak J, Williams SR, Gadian DG, Noble M: Proton nuclear magnetic resonance spectroscopy unambiguously identifies different neural cell types. J Neurosci 1993, I3(3):981-989.

24. Lentz MR, Kim JP, Westmoreland SV, Greco JB, Fuller RA, Ratai EM, He J, Sehgal PK, Halpern EF, Lackner AA, et al.: Quantitative neuropathologic correlates of changes in ratio of $\mathbf{N}$-acetylaspartate to creatine in macaque brain. Radiology 2005, 235(2):461-468.

25. Williams K, Westmoreland S, Greco J, Ratai E, Lentz M, Kim WK Fuller RA, Kim JP, Autissier P, Sehgal PK, et al:: Magnetic resonance spectroscopy reveals that activated monocytes contribute to neuronal injury in SIV neuroAIDS. I Clin Invest 2005, I I 5(9):2534-2545

26. Lentz MR, Westmoreland SV, Lee V, Ratai EM, Halpern EF, Gonzalez RG: Metabolic markers of neuronal injury correlate with SIV CNS disease severity and inoculum in the macaque model of neuroAIDS. Magn Reson Med 2008, 59(3):475-484.

27. Lentz MR, Lee V, Westmoreland SV, Ratai EM, Halpern EF, Gonzalez RG: Factor analysis reveals differences in brain metabolism in macaques with SIVIAIDS and those with SIV-induced encephalitis. NMR Biomed 2008, 2 I (8):878-887.

28. Blusztajn JK, Wurtman RJ: Choline and cholinergic neurons. Science | 983, 22 I(46 II):6| 4-620.

29. Chong WK, Sweeney B, Wilkinson ID, Paley M, Hall-Craggs MA, Kendall BE, Shepard JK, Beecham M, Miller RF, Weller IV, et al.: Proton spectroscopy of the brain in HIV infection: correlation with clinical, immunologic, and MR imaging findings. Radiology 1993, I88(I): II9-124.

30. Meyerhoff D], Bloomer C, Cardenas V, Norman D, Weiner MW, Fein $\mathrm{G}$ : Elevated subcortical choline metabolites in cognitively and clinically asymptomatic HIV+ patients. Neurology 1999, 52(5):995-1003.

31. Kim JP, Lentz MR, Westmoreland SV, Greco JB, Ratai EM, Halpern E, Lackner AA, Masliah E, Gonzalez RG: Relationships between astrogliosis and IH MR spectroscopic measures of brain choline/creatine and myo-inositol/creatine in a primate model. AJNR Am J Neuroradiol 2005, 26(4):752-759.

32. Brand A, Richter-Landsberg C, Leibfritz D: Multinuclear NMR studies on the energy metabolism of glial and neuronal cells. Dev Neurosci 1993, I5(3-5):289-298.

33. Chang L, Ernst T, Witt MD, Ames N, Gaiefsky M, Miller E: Relationships among brain metabolites, cognitive function, and viral loads in antiretroviral-naive HIV patients. Neuroimage 2002, I7(3): 1638-1648

34. Gartner S: HIV infection and dementia. Science 2000 287(5453):602-604.

35. Liu Y, Tang XP, McArthur JC, Scott J, Gartner S: Analysis of human immunodeficiency virus type I gpl60 sequences from a patient with HIV dementia: evidence for monocyte trafficking into brain. I Neurovirol 2000, 6(Suppl I):S70-8I.

36. Meyerhoff DJ, MacKay S, Poole N, Dillon WP, Weiner MW, Fein G: $\mathrm{N}$-acetylaspartate reductions measured by IH MRSI in cognitively impaired HIV-seropositive individuals. Magn Reson Imaging 1994, I 2(4):653-659.

37. Chong WK, Paley M, Wilkinson ID, Hall-Craggs MA, Sweeney B, Harrison MJ, Miller RF, Kendall BE: Localized cerebral proton MR spectroscopy in HIV infection and AIDS. AJNR Am J Neuroradiol I994, I5(I):2I-25.

38. Barker PB, Lee RR, McArthur JC: AIDS dementia complex: evaluation with proton MR spectroscopic imaging. Radiology 1995, 195(I):58-64

39. Meyerhoff DJ, MacKay S, Bachman L, Poole N, Dillon WP, Weiner MW, Fein G: Reduced brain $\mathbf{N}$-acetylaspartate suggests neuronal loss in cognitively impaired human immunodeficiency virus-seropositive individuals: in vivo I $\mathrm{H}$ magnetic resonance spectroscopic imaging. Neurology 1993, 43(3 Pt I):509-5I5.

40. Tracey I, Carr CA, Guimaraes AR, Worth JL, Navia BA, Gonzalez RG Brain choline-containing compounds are elevated in HIVpositive patients before the onset of AIDS dementia complex: A proton magnetic resonance spectroscopic study. Neurology 1996, 46(3):783-788.

4I. Thompson PM, Dutton RA, Hayashi KM, Toga AW, Lopez OL, Aizenstein HJ, Becker JT: Thinning of the cerebral cortex visualized in HIVIAIDS reflects CD4+ T lymphocyte decline. Proc Natl Acad Sci USA 2005, 102(43): 15647-15652. 
42. Marcus CD, Taylor-Robinson SD, Sargentoni J, Ainsworth JG, Frize G, Easterbrook PJ, Shaunak S, Bryant DJ: I H MR spectroscopy of the brain in HIV-I-seropositive subjects: evidence for diffuse metabolic abnormalities. Metab Brain Dis 1998, I 3(2): 123-I36.

43. Sacktor N, Skolasky RL, Ernst T, Mao X, Selnes O, Pomper MG, Chang L, Zhong K, Shungu DC, Marder K, et al.: A multicenter study of two magnetic resonance spectroscopy techniques in individuals with HIV dementia. J Magn Reson Imaging 2005, 2I(4):325-333.

44. Taylor MJ, Schweinsburg BC, Alhassoon OM, Gongvatana A, Brown GG, Young-Casey C, Letendre SL, Grant I: Effects of human immunodeficiency virus and methamphetamine on cerebral metabolites measured with magnetic resonance spectroscopy. J Neurovirol 2007, I3(2): 150-159.

45. Chang L, Lee PL, Yiannoutsos CT, Ernst T, Marra CM, Richards T, Kolson D, Schifitto G, Jarvik JG, Miller EN, et al.: A multicenter in vivo proton-MRS study of HIV-associated dementia and its relationship to age. Neuroimage 2004, 23(4): I336-I347.

46. Williams KC, Hickey WF: Central nervous system damage, monocytes and macrophages, and neurological disorders in AIDS. Annu Rev Neurosci 2002, 25:537-562.

47. Paul RH, Yiannoutsos CT, Miller EN, Chang L, Marra CM, Schifitto G, Ernst T, Singer E, Richards T, Jarvik GJ, et al.: Proton MRS and neuropsychological correlates in AIDS dementia complex: evidence of subcortical specificity. J Neuropsychiatry Clin Neurosci 2007, I 9(3):283-292.

48. Nagae-Poetscher LM, McMahon M, Braverman N, Lawrie WT Jr, Fatemi A, Degaonkar M, Horska A, Pomper MG, Chacko VP, Barker PB: Metabolites in ventricular cerebrospinal fluid detected by proton magnetic resonance spectroscopic imaging. J Magn Reson Imaging 2004, 20(3):496-500.

49. Pfefferbaum A, Adalsteinsson E, Sullivan EV: Cortical NAA deficits in HIV infection without dementia: influence of alcoholism comorbidity. Neuropsychopharmacology 2005, 30(7): I392-1399.

50. Kodama T, Mori K, Kawahara T, Ringler DJ, Desrosiers RC: Analysis of simian immunodeficiency virus sequence variation in tissues of rhesus macaques with simian AIDS. I Virol 1993 67(II):6522-6534.

5I. Webb PG, Sailasuta N, Kohler SJ, Raidy T, Moats RA, Hurd RE: Automated single-voxel proton MRS: technical development and multisite verification. Magn Reson Med 1994, 3 I (4):365-373.

52. Bottomley PA: Spatial localization in NMR spectroscopy in vivo. Ann N Y Acad Sci 1987, 508:333-348.

53. Haase A, Frahm J, Hanicke W, Matthaei D: IH NMR chemical shift selective (CHESS) imaging. Phys Med Biol 1985, 30(4):34I-344.

54. Provencher SW: Estimation of metabolite concentrations from localized in vivo proton NMR spectra. Magn Reson Med 1993, 30(6):672-679.

55. Barker PB, Soher BJ, Blackband SJ, Chatham JC, Mathews VP, Bryan RN: Quantitation of proton NMR spectra of the human brain using tissue water as an internal concentration reference. NMR Biomed 1993, 6(I):89-94.

56. Constans JM, Meyerhoff DJ, Gerson J, MacKay S, Norman D, Fein G, Weiner MW: H-I MR spectroscopic imaging of white matter signal hyperintensities: Alzheimer disease and ischemic vascular dementia. Radiology 1995, 197(2):517-523.

57. Suryanarayana K, Wiltrout TA, Vasquez GM, Hirsch VM, Lifson JD: Plasma SIV RNA viral load determination by real-time quantification of product generation in reverse transcriptasepolymerase chain reaction. AIDS Res Hum Retroviruses 1998, 14(2): 183-189.

58. Desrosiers RC, Lifson JD, Gibbs JS, Czajak SC, Howe AY, Arthur LO, Johnson RP: Identification of highly attenuated mutants of simian immunodeficiency virus. J Virol |998, 72(2): |43|-| 437.
Publish with Biomed Central and every scientist can read your work free of charge

"BioMed Central will be the most significant development for disseminating the results of biomedical research in our lifetime. "

Sir Paul Nurse, Cancer Research UK

Your research papers will be:

- available free of charge to the entire biomedical community

- peer reviewed and published immediately upon acceptance

- cited in PubMed and archived on PubMed Central

- yours - you keep the copyright

Submit your manuscript here:

http://www.biomedcentral.com/info/publishing_adv.asp
BiolMedcentral 